\title{
INCLUSIÓN EDUCATIVA A NIVEL UNIVERSITARIO: \\ ESTUDIO DE CASOS DE ESTUDIANTES SORDO PARLANTES
}

\section{INCLUSIVE UNIVERSITY EDUCATION: CASE STUDY OF HEARING-IMPAIRED STUDENTS}

\author{
ELENA CARRERA SEGOVIA ${ }^{1}$
}

SUYANA ARCOS VILLAGÓMEZ²

Recibido: 15 de junio de 2018 Aceptado: 29 de enero de 2018

\footnotetext{
${ }_{1}^{1}$ Pontificia Universidad Católica del Ecuador, Centro de Psicología Aplicada, Quito, Ecuador (escarrera@puce.edu.ec)

${ }^{2}$ Pontificia Universidad Católica del Ecuador, Facultad de Ingeniería de Sistemas, Quito, Ecuador (sarcos@puce.edu.ec)
} 
네닌 72 


\section{INCLUSIÓN EDUCATIVA A NIVEL UNIVERSITARIO: \\ ESTUDIO DE CASOS DE ESTUDIANTES SORDO PARLANTES}

\section{INCLUSIVE UNIVERSITY EDUCATION: \\ CASE STUDY OF HEARING-IMPAIRED STUDENTS}

Elena Carrera Segovia, Suyana Arcos Villagómez

PALABRAS CLAVES: inclusión, educación superior, diversidad, sordos

KEY WORDS: inclusive education, undergraduate studies, diversity, hearingimpaired

\section{RESUMEN}

Esta investigación fue un análisis exploratorio de las condiciones de estudio de los estudiantes sordo parlantes en la PUCE-Quito desde el 2008 al 2016. Se planteó la hipótesis de que los estudiantes que cursaron carreras en la PUCE-Quito han sido una muestra de la existencia de un nivel de inclusión.
Los resultados señalaron que la PUCE-Quito cuenta con la decisión política para llevar a cabo procesos inclusivos y mantiene algunas actividades relacionadas con este tema como el acceso de las personas en situación de discapacidad y algunas investigaciones que se encuentran en proceso. 
Con el propósito de impulsar una cultura de inclusión se encontró que se requiere mantener procesos permanentes de sensibilización a la comunidad universitaria sobre temas de inclusión educativa con equidad.

En la práctica se evidenció que el personal docente universitario necesita ampliar su formación sobre sordera porque se facilitaría el diseño de los procesos de enseñanza, aprendizaje y adap- taciones curriculares adecuadas para los estudiantes sordo parlantes.

Como producto de esta investigación se elaboró una guía y un video para la inclusión de los estudiantes sordo parlantes a nivel de educación superior en la PUCE-Quito con el propósito de contribuir al esfuerzo que está realizando la Universidad en el tema de la inclusión educativa.

\section{ABSTRACT}

This research was an exploratory analysis of the study conditions for deaf-speaking students at PUCE-Quito from 2008 to 2016. It was hypothesized that the students who studied at PUCE-Quito serve as an example of the existence of the level of inclusion.

The results indicated that PUCE-Quito has the political power of decision to carry out inclusive processes and maintains some activities related to this issue, such as access for people with disabilities and certain in-process research.

In order to promote a culture of inclusion, the findings showed that it is necessary to educate the university community regarding issues of educational inclusion with equity.

In practice, it was evident that the university teaching staff needs to expand training processes for hearing-impaired students, as this would facilitate design of the teaching, learning and curricular adaptation processes suitable for these students.

As a result of this research, a guide and a video for the inclusion of hearing-impaired students at PUCE-Quito was created, with the purpose of contributing to the effort that the University is making in advancing educational inclusion. 


\section{INTRODUCCIÓN}

La escasa presencia de los estudiantes sordo parlantes ${ }^{1}$ en la Universidad motivó la reflexión sobre cómo ofrecer igualdad de oportunidades para que la educación fuera accesible y para todos, así como el repensar la manera de apoyar a la Universidad para que esta funcione como un sistema educativo inclusivo considerando que, a la par, se requiere cumplir con las exigencias académicas que cada vez son mayores.

La inclusión es un concepto que superó la concepción de los normales, los oyentes y los que tienen problemas. Su énfasis está en la riqueza de la diversidad que tenemos todas las personas: diferentes necesidades educativas, género, color de la piel, la sordera, entre otros.

El Comité sobre los Derechos de las Personas con Discapacidad de las Naciones Unidas (2014), según el informe presentado por el Ecuador, señala que el promedio de escolaridad de las personas con discapacidad es de tres a cuatro años frente a la media nacional de nueve años. A partir de esta información, inferimos que acceder a la Universidad es todo un reto para el estudiante en situación de sordera.
La Convención sobre los Derechos de las Personas con Discapacidad (2008) es un instrumento jurídico que refleja el acuerdo internacional de que las personas en situación de discapacidad no deben ser normalizadas. Por el contrario, se celebra su diversidad y, al haber sido acordada por las Naciones Unidas, se convierte en un estándar universal cuyos principios son el respeto por la diferencia, la igualdad de oportunidades, la participación efectiva en la sociedad, entre otros. De la misma manera, señala la Convención que los países asegurarán que las personas en situación de discapacidad tengan acceso a la educación superior a través de la realización de ajustes razonables.

Ainscow (como se cita en Echeita, 2014), Profesor de Educación de la Universidad de Manchester, señala que el concepto de inclusión se apoya en los siguientes elementos fundamentales: la inclusión es un proceso porque es una tarea interminable, la inclusión debe identificar y remover barreras de exclusión, discriminación y marginación que impiden el ejercicio efectivo de los derechos, y la inclusión está relacionada

\footnotetext{
${ }^{1}$ La bibliografía argentina hace mención al concepto de sordo parlante mientras que la bibliografía española señala sordo poslocutivo. Al ser términos que se encuentran en construcción, para esta investigación se utilizó el concepto de sordo parlante que es la persona que nació oyente, luego ensordeció y es usuario de ayudas técnicas como los audífonos.
} 
con la presencia de los estudiantes en el ambiente educativo y su participación se evidencia en el bienestar personal y social como miembro de una comunidad y en los resultados de aprendizaje que aseguren el conocimiento para una futura inclusión laboral.

Simon y Echeita (como se cita en Escribano, A.; Martínez, A., 2013) señalan que la inclusión por naturaleza es un proceso esencialmente controversial porque enfrenta decisiones que involucran aspectos tanto positivos como negativos dependiendo del punto de vista desde donde se analice la situación.

No existe una decisión, una política o una práctica educativa que asegure o garantice una inclusión al ciento por ciento, porque incide el factor recursos y apoyos financieros, influye si existe una débil convicción por parte de los dirigentes políticos sobre el proceso de inclusión educativa, incide los perfiles educativos que son renuentes a los valores y las prácticas favorecedoras de un proceso de inclusión (Echeita, Simon, López y Urbina, (como se cita en Escribano, A.; Martínez, A., 2013).

La PUCE-Quito, sensible ante esta realidad y en su empeño por dinamizar la inclusión educativa universitaria, ha incluido a estudiantes sordo parlantes quienes son el motivo de esta investigación.

El Consejo Nacional de Discapacidades (CONADIS), en diciembre de 2016, señaló un total de 415.500 personas en situación de discapacidad en el Ecuador registradas por provincia y se cita como fuente el Ministerio de Salud Pública. Esta fuente señaló que a nivel nacional existen 53.079 personas con discapacidad auditiva, de las cuales en la Provincia de Pichincha se registran 9.940 personas y en el Distrito Metropolitano de Quito se registran 8.723 personas sordas. A continuación, una tabla que muestra la realidad de las personas con discapacidad en el Ecuador:

Tabla 1: Personas con discapacidad en el Ecuador a diciembre 2016.

\begin{tabular}{|l|r|}
\hline PERSONAS CON DISCAPACIDAD EN EL ECUADOR & 415.500 \\
\hline Con Discapacidad Auditiva a nivel nacional & 53.079 \\
\hline - En la Provincia de Pichincha & 9.940 \\
\hline - En el Distrito Metropolitano de Quito & $\mathbf{8 . 7 2 3}$ \\
\hline
\end{tabular}

Fuente: Ministerio de Salud Pública del Ecuador

Elaborador por: ECS abril 2017 


\section{OBJETIVO GENERAL}

Describir cuáles son las condi- casos de estudio y la elaboración de una ciones de estudio para los estudiantes guía para la inclusión a nivel de educasordo parlantes en la PUCE-Quito a tra- ción superior.

vés de un análisis exploratorio de cinco

\section{MATERIAL Y MÉTODOS}

El estudio fue realizado en la Pon- dos para el período 2008-2016. A contitificia Universidad Católica del Ecuador nuación, se presenta una tabla que reco(PUCE) sede Quito. La Dirección General ge la información proporcionada por la de Estudiantes de la Universidad informó DGE de la PUCE:

sobre el registro de 21 estudiantes sor-

TABLA 2: Estudiantes sordos matriculados en la PUCE durante el período 2008-2016

\begin{tabular}{|c|c|c|}
\hline Nr. & SEMESTRE & ESTUDIANTES SORDOS \\
\hline 1 & 1 Semestre 2008-2009 & 1 \\
\hline 2 & 2 Semestre 2008-2009 & 0 \\
\hline 3 & 1 Semestre 2009-2010 & 0 \\
\hline 4 & 2 Semestre 2009-2010 & 1 \\
\hline 5 & 1 Semestre 2010-2011 & 0 \\
\hline 6 & 2 Semestre 2010-2011 & 2 \\
\hline 7 & 1 Semestre 2011-2012 & 0 \\
\hline 8 & 2 Semestre 2011-2012 & 0 \\
\hline 9 & 1Semestre 2012-2013 & 2 \\
\hline 10 & 2 Semestre 2012-2013 & 1 \\
\hline 11 & 1Semestre 2013-2014 & 0 \\
\hline 12 & 2Semestre 2013-2014 & 5 \\
\hline 13 & 1 Semestre 2014-2015 & \\
\hline
\end{tabular}




\begin{tabular}{|c|c|c|}
\hline 14 & 2Semestre 2014-205 & 0 \\
\hline 15 & 1 Semestre 2015-2016 & 7 \\
\hline TOTAL & & 21 \\
\hline
\end{tabular}

Fuente: Dirección General de Estudiantes PUCE

Elaborado por: ECS a febrero de 2017

Se privilegió a los estudiantes ríamos con la aprobación del Comité de con carné del CONADIS y que hubieran Ética de la Investigación de la PUCE de cursado mínimo cuatro semestres en la realizar un análisis exploratorio de cinco carrera elegida. De esta manera, cumpli- casos de estudio.

TABLA 3: Estudiantes pre-seleccionados para solicitar su colaboración en la investigación.

\begin{tabular}{|c|l|l|c|}
\hline Nr. & FACULTAD & CARRERA & SEMESTRES CON BECA \\
\hline 1 & ARQUITECTURA & Arquitectura & 8 \\
\hline 2 & ADMINISTRACIÓN & Administración & 3 \\
\hline 3 & ADMINISTRACIÓN & Administración & 2 \\
\hline 4 & $\begin{array}{l}\text { ECONOMÍA (1ra opción) ADMINISTRACIÒN } \\
\text { (2da opción) }\end{array}$ & Contabilidad y Auditoría & 9 \\
\hline 5 & $\begin{array}{l}\text { ECONOMÍA (1ra. opción) } \\
\text { (IENCIAS HUMANAS }^{\text {(2da Opción) }}{ }^{*}\end{array}$ & $\begin{array}{l}\text { Geografía y Medio Am- } \\
\text { biente }\end{array}$ & 8 \\
\hline 6 & EDUCACIÓN & Modalidad Semipresencial & 2 \\
\hline 7 & ENFERMERÍA & Terapia Física & 11 \\
\hline 8 & INGENIERÍA & Ingeniería Civil & 2 \\
\hline 9 & MEDICINA & Medicina & 7 \\
\hline 10 & PSICOLOGÍA & Psicología Organizacional & 2 \\
\hline 11 & PSICOLOGÍA & Psicología Clínica & 4 \\
\hline
\end{tabular}

* Los estudiantes pasaron por dos facultades diferentes.

Fuente: Dirección General de Estudiantes PUCE a marzo de 2016

Elaborador por: ECS a febrero de 2017 
Cuando se estableció el primer contacto con los estudiantes pre-seleccionados se obtuvieron los siguientes resultados: siete estudiantes expresaron su resistencia a colaborar con la encuesta y la investigación. Los argumentos que sostuvieron fueron: no disponer de tiempo para la entrevista y no haber necesitado ayuda para su situación de discapacidad a pesar de haber recibido una beca de discapacidad proporcionada por la Universidad y tener carné del CONADIS. De este grupo, tres estudiantes fueron contactados varias veces - de acuerdo a sus pedidos-, no obstante del segui- miento realizado, finalmente expresaron su resistencia hacia la investigación.

Posteriormente, fueron retirados de la muestra aquellos estudiantes que respondieron no haber necesitado ayuda por parte de la Universidad. Se infirió que se trató de la tendencia general del estudiante a simular que oye y a ocultar la sordera por considerarla una falta - una carencia que podría reflejarse en una limitación cognitiva frente a sus pares-, en lugar de identificarla como una particularidad de la persona sorda.

Cuatro estudiantes expresaron abiertamente su deseo de colaboración:

TABLA 4: Muestra para la investigación.

\begin{tabular}{|c|l|l|c|}
\hline$\#$ & FACULTAD & CARRERA & $\begin{array}{l}\text { SEMESTRES } \\
\text { CON BECA DE DISCAPACIDAD }\end{array}$ \\
\hline 11 & $\begin{array}{l}\text { ECONOMÍA (1ra opción) } \\
\text { ADMINISTRACIÒn (2da opción) }\end{array}$ & Contabilidad y Auditoría & 9 \\
\hline 22 & $\begin{array}{l}\text { ECONOMÍ́ (1ra opción) } \\
\text { (IENCIAS HUMANAS (2da opción)* }\end{array}$ & $\begin{array}{l}\text { Geografía y Medio Am- } \\
\text { biente }\end{array}$ & 8 \\
\hline 33 & EDUCACIÓN & Modalidad Semipresencial & $\begin{array}{c}2 \\
(4)^{* *}\end{array}$ \\
\hline 44 & ENFERMERÍ́A & Terapia Física & 11 \\
\hline
\end{tabular}

* Los estudiantes pasaron por dos facultades diferentes.

** La estudiante cursó cuatro semestres de la carrera: primer y segundo semestres sin beca de discapacidad. Fuente: Dirección General de Estudiantes PUCE - marzo de 2016

Elaborador por: ECS, marzo de 2017

Una participante recibió beca de discapacidad durante nueve semestres y no logró superar el tercer nivel de la ca- rrera. Otra participante cursó cuatro semestres de la carrera: primer y segundo semestres sin beca de discapacidad. 
Para la elaboración de la encuesta se tomó como referencia el Index para la Inclusión de (Booth, T.; Ainscow, M.; Kingston, D., 2006) que señala tres instancias a ser articuladas: cultura, políticas y prácticas inclusivas.

Finalmente, se realizó una entrevista en profundidad a cada participante. Se procedió a la explicación del contenido del Consentimiento Informado. Luego de su comprensión y firma, se entregó una copia del documento para el estudiante. Cada participante llenó un cuestionario que reflejó cuatro momentos claves de la vida universitaria:

Primer Momento: Datos sobre el estudiante

Segundo Momento: Datos sobre la accesibilidad del estudiante en la Educación Superior

Tercer Momento: Datos sobre la permanencia del estudiante en la Universidad

Cuarto Momento: Datos sobre la culminación de la carrera universitaria

\section{RESULTADOS}

\section{PRIMER MOMENTO: DATOS DEL ESTUDIANTE}

Los participantes que aceptaron colaborar con este estudio corresponden a las facultades de: Ciencias de la Educación (modalidad semi-presencial); Administración (Carrera de Contabilidad y Auditoría); Ciencias Humanas (Carrera de Geografía) y Enfermería (Carrera de Terapia Física) con modalidad presencial. La muestra estuvo compuesta por un hombre y tres mujeres. De acuerdo al porcentaje señalado en el carné del CONADIS, dos participantes reflejan pérdida leve (30\% y 33\%) y dos presentan pérdida moderada (41\% y 58\%). 
TABLA 5: Características de la muestra según carrera, género, porcentaje y grado de pérdida auditiva

\begin{tabular}{|l|l|l|l|l|l|}
\hline$\#$ & FACULTAD - CARRERA & GÉNERO & \% CARNÉ & GRADO DE PÉRDIDA & $\begin{array}{l}\text { PERCEPCIÓN DESU } \\
\text { SORDERA }\end{array}$ \\
\hline 1 & CIENCIAS HUMANAS - Geografía & Hombre & 39 subió a 41 & Moderada & Profunda \\
\hline 2 & ADMINISTRACIÓN - Contabilidad & Mujer & 30 & Leve & Moderada \\
\hline 3 & $\begin{array}{l}\text { CIENCIAS DE LA EDUCACIÓN - } \\
\text { Modalidad Semipresencial }\end{array}$ & Mujer & 58 bajó a 46 & Moderada & Profunda \\
\hline 4 & ENFERMERíA - Terapia Física & Mujer & 33 & Leve & Moderada \\
\hline
\end{tabular}

Elaboración: ECS, marzo de 2017

Dos participantes por diferentes razones actualizaron su carné del CONADIS y, en el primer caso, el porcentaje varió de 39 a 41\%, consideramos la subida una tendencia razonable; en el segundo caso, el porcentaje bajó de 58 a 46\%. Si bien ambos porcentajes se mantienen en el rango de pérdida moderada, se reflexionó que la discapacidad nunca va hacia menos sino hacia más, lo cual refleja que los indicadores del CONADIS para definir el porcentaje real de pérdida auditiva no se ajustan a la realidad del país e inciden directamente en la persona sorda.

Los estudiantes participantes señalaron otra realidad en cuanto a cómo perciben su sordera. Aquellos que tienen un nivel moderado (50\%) de sordera indicaron percibirla como profunda (90\%). Se infirió que la razón es porque sienten barreras de comunicación y de acceso a la información en su entorno.

Dos participantes adquirieron la sordera desde el nacimiento la misma que fue detectada por la familia y el especialista de la salud (Pediatra). Para los otros dos casos, la sordera fue adquirida, la una de manera heredada y la otra debido a un accidente, ambos casos fueron detectados por la familia y sucedió en edad adulta. 
TABLA 6: Momento de instauración de la sordera

\begin{tabular}{|c|c|c|c|c|}
\hline$\#$ & CARRERA & INSTAURACIÓN DE LA SORDERA & TIPO DE SORDERA & USA AUDíFONO \\
\hline 11 & Geografía & Al nacer & Bilateral & SI \\
\hline 2 & Contabilidad & Al nacer & Bilateral & NO \\
\hline 33 & Educación & Herencia* & Bilateral & SI \\
\hline 44 & Terapia F́ísica & Accidente* $^{*}$ & Unilateral & NO \\
\hline
\end{tabular}

*Dos de los participantes tienen familia donde se presentan situaciones de sordera.

Elaboración: ECS- marzo de 2017

Tres participantes presentaron sordera bilateral y una unilateral. Dos participantes son usuarios de audífonos, la tercera indicó que debería usar audífonos pero al ser muy caros estos se vuelven inaccesibles, y la cuarta participante no tuvo posibilidad de usar audífono porque perdió el nervio auditivo en un accidente.

\section{Sobre la expresión oral y escrita}

Dos participantes recibieron terapia de lenguaje en un promedio de cinco años, expresaron comunicarse oralmente y por escrito e indicaron que la calidad de su redacción escrita es regular.

Cuatro participantes señalaron que realizan lectura labial y que, cuando no captan la información, solicitan que les repitan.

TABLA 7: Tipo de Comunicación

\begin{tabular}{|c|c|c|c|c|c|c|c|}
\hline Nr. & CARRERA & ORAL & $\begin{array}{l}\text { TERAPIA DE LEN- } \\
\text { GUAJE }\end{array}$ & $\begin{array}{l}\text { ESPANOOL } \\
\text { ESCRITO }\end{array}$ & $\begin{array}{c}\text { CALLDAD DEREDAC- } \\
\text { CIÓN ESCRITA }\end{array}$ & $\begin{array}{l}\text { LECTURA } \\
\text { LABIAL }\end{array}$ & $\begin{array}{l}\text { LENGUA DE } \\
\text { SEÑAS }\end{array}$ \\
\hline 1 & Geografía & SÍ & Promedio 5 años & sí & Regular & Sí & NO \\
\hline 2 & Contabilidad & Sí & Promedio 5 años & SÍ & Regular & Sí & NO \\
\hline 3 & Educación & Sí & No aplica & sí & Excelente & SÍ & sí \\
\hline 4 & Terapia Física & SÍ & № aplica & sí & Excelente & Sí & NO \\
\hline
\end{tabular}


Tres participantes señalaron que no conocen la Lengua de Señas Ecuatoriana pero que les gustaría aprenderla. Una participante indicó estar aprendiendo este idioma en la Asociación de Sordos de Pichincha (abril 2016).

\section{Sobre la interacción social}

El Manual sobre la Sordera (2014) señala que la gran mayoría de los estudiantes sordo parlantes no son partícipes de la Comunidad Sorda porque han recibido el mensaje de disimular y ocultar su sordera. Solo una participante señala pertenecer y formar parte de varios grupos fuera de la Universidad como forma de extender sus contactos y su vida social.

\section{SEGUNDO MOMENTO: ACCESIBILIDAD A LA EDUCA- CIÓN SUPERIOR}

Los cuatro participantes no registraron haber rendido el examen del SENESCYT pero sí aprobaron el examen de admisión de la PUCE y fueron entrevistados por la Dirección General de Estudiantes.

Durante la entrevista en la Dirección General de Estudiantes, cuatro participantes señalaron que sabían qué contestar frente a las preguntas de la Dirección pese a la falta de apoyo técnico visual que pudo haber facilitado la comunicación como son el uso de un Power Point, subtítulos, la entrega de información impresa, la realización de preguntas por escrito.

Dos participantes señalaron que las preguntas fueron claras y que les gus- tó conversar con un representante de la Universidad acerca de sí mismos.

Tres participantes señalaron que no fueron informados sobre las ayudas técnicas para su situación de sordera y los cuatro participantes señalaron que no se les proporcionó información visual o con subtítulos sobre la carrera elegida. No obstante, dos participantes señalaron que se entusiasmaron por iniciar el estudio en la Universidad.

A dos participantes les resultó muy fácil tomar la decisión sobre qué carrera estudiar en la Universidad; a un participante le resultó fácil y a un participante le resultó difícil. 


\section{Sobre el acceso a la información, las} alternativas técnicas y los apoyos visuales.

La encuesta realizó un sondeo sobre el acceso a la información, las alternativas técnicas y los apoyos visuales que se podrían ofrecer al estudiante al ingresar a la Universidad y definió tres categorías de respuesta:

a. Se me ofreció información, alternati- vas y ayudas.

b. Se me ofreció y actualmente estoy haciendo uso de ella.

c. No se me ofreció pero me hubiera sido útil.

El siguiente cuadro se resume las preguntas en relación al acceso a la información, a las alternativas técnicas y a los apoyos visuales.

TABLA 8: Acceso a la información, alternativas técnicas y apoyos visuales

\begin{tabular}{|c|c|c|c|c|}
\hline PREGUNTAS & SEME OFRECIÓ INFORMACIÓN & $\begin{array}{c}\text { SE ME OFRECIÓ Y ESTOY } \\
\text { HACIENDO USO }\end{array}$ & $\begin{array}{c}\text { NO SE ME OFRECIÓ PERO ME } \\
\text { HUBIERA SIDO ÚTIL }\end{array}$ & TOTAL \\
\hline 25 & 13 & 7 & 24 & 44 \\
\hline$\%$ & 29.54 & 15.90 & 54.54 & 100 \\
\hline
\end{tabular}

Elaboración: ECS- marzo de 2017

Sobre el acceso a la información, alternativas técnicas y apoyos visuales, se realizaron 25 preguntas de las cuales el $29.54 \%$ reflejaron que se le ofreció; el $15.90 \%$ señalaron que se les ofreció y están haciendo uso; y un 54.54\% indicaron que no se les ofreció pero que les hubiera sido de utilidad.

Se obtuvieron los siguientes resultados:

1. Te gustaría conocer la experiencia universitaria de estudiantes de tu carrera: dos participantes expresaron que se les ofreció la alternativa y dos participantes señalaron que no se les ofreció pero les hubiera sido útil.

2. Te gustaría conocer la experiencia universitaria de estudiantes sordo parlantes: a una participante se le ofreció esta opción e hizo uso de ella; a tres participantes no les ofrecieron pero consideran que les hubiera sido de utilidad.

3. Encuentros con personal de apoyo a la discapacidad auditiva: un par- 
ticipante señaló que se le ofreció esta alternativa; tres participantes señalaron que no se les ofreció esta opción pero les hubiera sido de utilidad.

\section{Información sobre la ayuda téc-} nica Frecuencia Modulada (FM) 2:-a un participante se le ofreció la información de la FM; a tres participantes no se les ofreció la información pero les hubiera sido de utilidad.

5. Información sobre apoyos visuales (estenotipia 3 , power point): a dos participantes se les ofreció la información e hicieron uso de ella; a los otros dos estudiantes no se les ofreció la información pero les hubiera sido de utilidad.

\section{Información sobre la Ley de}

Discapacidades, LOES y Derechos Hu-
manos: a una persona se le ofreció la información sobre derechos; a tres partici- pantes no se les ofreció pero les hubiera sido de utilidad.

7. Información sobre los servicios de la PUCE (becas, biblioteca, servicio de informática): a dos participantes se les ofreció la información sobre los servicios de la PUCE; a un participante se le ofreció la información e hizo uso de ella y al segundo estudiante no se le ofreció pero le hubiera sido de utilidad.

8. Información sobre actividades culturales y deportivas: a dos participantes se les ofreció la información sobre cultura y deportes; a un participante se le ofreció la información e hizo uso de ella y al otro no se le ofreció pero le hubiera sido de utilidad.

\section{Ampliar información sobre el} proceso de admisión: a dos participantes se les ofreció información sobre admisio-

\footnotetext{
${ }^{2}$ Frecuencia Modulada (FM): es un apoyo que mejora la recepción del lenguaje y consiste en un micrófono para el docente que es el emisor y un receptor para el estudiante sordo parlante. El emisor capta la voz de la persona que habla y la envía al receptor a través de los audífonos o implante coclear. Este sistema permite que la información sonora del emisor llegue directa y fielmente del orador al estudiante posibilitando la disminución de la interferencia sonora ambiental como es el caso del aula de clase. Fuente: INSOR 2004 https://www.sonoraudifonos.com/sonor-audifonos/equipos-fm-frecuencia-modulada extraída en enero 2017.

${ }^{3}$ Estenotipia: es un método de escritura rápida que utiliza un teclado llamado máquina de estenotipia y
gracias al cual se ejecutan pulsaciones con una o más teclas presionadas simultáneamente. Mediante esta
tecnología, ha sido posible integrar subtítulos a las imágenes, lo cual resulta de mucha ayuda cuando se
hace en tiempo real y permite que personas sorda parlantes tengan acceso a lo que está mostrando la
televisión, una película, video, un congreso, seminario, etc. El subtitulado o Closed Caption (función CC es
activado en su TV a través del control remoto o también en Youtube) es una herramienta que hoy, unida
a la televisión digital, podría mejorar la calidad de vida de personas que tienen su capacidad auditiva
disminuida. Fuente: https://ayudatec.cl/2011/10/11/¿que-es-la-estenotipia/ extraída en diciembre 2016.
} 
nes; a un participante se le ofreció la información del proceso e hizo uso de ella y al otro no se le ofreció pero le hubiera sido de utilidad.

\section{Información sobre el primer} año de estudios y las expectativas: a un participante se le ofreció la información; a tres participantes no se les ofreció pero les hubiera sido de utilidad.

\section{Visitar la Universidad previa-} mente al ingreso a clases: a un participante se le ofreció visitar la Universidad; a tres participantes no se les ofreció pero les hubiera sido de utilidad.

12. Información sobre adaptaciones técnicas a los auditorios: implementación de Aro Magnético ticipantes señalan que no se les ofreció pero les hubiera sido de utilidad.

13. Entrega de los contenidos (libros y lecturas) al inicio de cada semestre: a un participante se le ofreció los contenidos; a tres participantes no se les ofreció pero les hubiera sido de utilidad.

14. Oportunidad de probar un día normal o una semana en la PUCE. con conferencias reales, etc.: a dos participantes se les ofreció la oportunidad; a dos participantes no se les ofreció pero les hubiera sido de utilidad.

15. Ser custodio de un receptor de Frecuencia Modulada (FM) adaptado a sus audífonos: Ios cuatro participantes señalaron que no se les ofreció pero les hubiera sido de utilidad.

16. Ser usuario de los Aros Magnéticos ubicados en los auditorios: los cuatro participantes señalaron que no se les ofreció pero les hubiera sido de utilidad.

17. Señales luminosas donde se difundan las novedades de los servicios de la PUCE: Ios cuatro participantes señalaron que no se les ofreció la opción de

\footnotetext{
${ }^{4}$ Aro Magnético o Bucle Magnético constituye una solución tecnológicamente sencilla para mejorar sustancialmente la calidad de la escucha; es un dispositivo que transforma el sonido en ondas magnéticas que son captadas por la prótesis auditiva (audífono o implante coclear). Un micrófono recoge la voz del emisor y la transmite de forma modulada mediante el cable magnético (UCM, 2012). Para su utilización, el usuario tiene que estar dentro de un campo magnético que se crea con la instalación del cable alrededor de la zona donde vaya a estar situada la persona sorda parlante (aula, auditorio, sala de reuniones, cines, teatros, salas de conferencias, mostradores de atención al público).

Fuente: Ayudando a oír mejor: el aro magnético de Eirea, G. (2014). Instituto de Ingeniería Eléctrica, Montevideo, https://iie.fing.edu.uy extraída en enero de 2017.
} 
señales luminosas pero les hubiera sido de utilidad.

18. Becas por discapacidad: tres participantes señalaron que se les ofreció la beca; un participante señaló que se le ofreció e hizo uso de ella.

19. La Biblioteca General de la PUCE facilitó los préstamos a mayor plazo: a un participante se le ofreció la información sobre la Biblioteca; a dos participantes se les ofreció la información e hicieron uso de ella y al otro no se le ofreció pero le hubiera sido de utilidad.

20. Videoteca con audio en español y con subtítulos en español: los cuatro participantes señalaron que no se les ofreció pero les hubiera sido de utilidad.

21. Sistema de subtitulación en directo (estenotipia computarizada; sistema de subtítulos automático): los cuatro participantes señalaron que no se les ofreció pero les hubiera sido de utilidad.

22. Apoyo para un mayor dominio de la lecto-escritura del español: los cuatro participantes señalaron que no se les ofreció pero les hubiera sido de utilidad.

23. Apoyo a través de un voluntario para asegurar una comunicación adecuada: los cuatro participantes señalaron que no se les ofreció pero les hubiera sido de utilidad.

\section{Aprendizaje de la Lengua de}

Señas Ecuatoriana: Ios cuatro participantes señalaron que no se les ofreció pero les hubiera sido de utilidad. La tendencia mundial es que todas las personas sordas se apropien de la Lengua de Señas independientemente de si son sordos profundos, sordos parlantes o sordos con implante coclear al aprovechar su destreza natural.

25. Subtitular la información que circula en la red televisiva de la PUCE: Ios cuatro participantes señalaron que no se les ofreció pero les hubiera sido de utilidad. 


\title{
TERCER MOMENTO: PERMANENCIA DEL ESTUDIANTE EN LA PUCE-QUITO
}

\author{
Cuadro resumen de las preguntas versidad.
}

en relación a la permanencia en la Uni-

Tabla 9: Sobre la permanencia del estudiante en la PUCE-Quito

\begin{tabular}{|c|c|c|c|c|}
\hline PREGUNTAS & SI & AVECES & NO & TOTAL \\
\hline 56 & 40 & 14 & 42 & 96 \\
\hline$\%$ & 41.66 & 14.58 & 43.75 & 100 \\
\hline
\end{tabular}

Elaboración: ECS- marzo de 2017

Se realizaron 56 preguntas de las cuales el $41.66 \%$ reflejaron que sí utilizan los servicios de la Universidad; el 14.58\% indicaron que a veces y un $43.75 \%$ señalaron que no.

Se obtuvieron los siguientes resultados:

1. En qué momento comunicó a la PUCE que es un estudiante con sordera (respuesta de opción múltiple): dos participantes comunicaron sobre su situación de sordera en la inscripción para el examen de admisión a la Universidad y en la primera semana del semestre; un participante señaló haber comunicado durante la entrevista previa al examen de admisión y después del primer año de estudios.

2. En la PUCE, quién conoce sobre su situación de sordera (respuesta de opción múltiple): tres participantes señalaron que sobre su situación de sordera conoce la Dirección General de Estudiantes (Admisiones y Bienestar Estudiantil), algunos docentes, los amigos y otros estudiantes de la PUCE; dos participantes señalaron que conoce el Docente Tutor y la Secretaría de la Facultad; y otro participante señaló que todos sus docentes y el Centro Médico.

3. Cómo se siente al explicar sobre sus necesidades: un participante señaló que no se siente nada cómodo; un participante señaló que no es cómodo; un participante señaló que bien y un participante expresó que bastante cómodo.

4. Tiene su propio computador portátil: tres participantes señalaron tener un computador portátil y un par- 
ticipante indicó no disponer de computador.

5. Tiene teléfono móvil con acceso al internet y varias aplicaciones: todos los participantes respondieron positivamente.

\section{Cuando necesita información} cómo y dónde suele consultar (respuesta de opción múltiple): tres participantes recurrieron a la familia y a los amigos; dos participantes consultaron a los docentes, Biblioteca General de la PUCE, en la WEB de la PUCE y otros sitios web; un participante buscó en los medios y redes sociales, envió mensajes de correo electrónico, en los periódicos y revistas, en películas y videos subtitulados y también preguntó al Tutor de la PUCE. Para todos los participantes quedaron excluidas las opciones al personal de apoyo a la discapacidad de la PUCE y al Grupo de Estudio.

\section{Durante sus estudios, recibió} ayuda en relación con su sordera: los cuatro participantes respondieron no haber recibido ayuda para la situación de sordera a pesar de tener un diagnóstico.

8. Qué apoyo adicional cree que le hubiera sido de utilidad (respuesta de opción múltiple): (a) cuatro participantes señalaron el contar con un profesor de apoyo, la ayuda de un voluntario para obtener información impresa de los contenidos de las materias y de la clase, contar con beca por discapacidad y con apoyo para asegurar una competencia comunicativa eficiente en el aula.

(b) tres participantes señalaron que dentro del aula les hubiera sido de utilidad aplicar cambios en la forma de realizar los trabajos de grupo, plantear alternativas al trabajo en grupo y trabajo individual, contar con grupos de apoyo para estudiar, contar con apoyos como la estenotipia, sistema nimio o ebean -que transforman el audio en texto- para ser utilizadas en las conferencias dictadas en los auditorios y contar con la entrega impresa de los contenidos de las materias previo al inicio del semestre.

(c) dos participantes señalaron el contar con un tutor durante toda la carrera y no uno diferente por cada semestre, cambiar la modalidad de los exámenes, de las evaluaciones (p.e. no examen oral en otro idioma), permiso para grabar las clases y pasar a texto vía estenotipia, un ordenador personal disponible en las aulas y salas de conferencias con software que transforme el audio a texto, subtitular las noticias que se transmiten vía la red televisiva de la PUCE, contar con aros 
magnéticos en aulas y auditorios, contar con una videoteca con audio en español y con subtítulos en español, en los auditorios y aulas contar con sistemas de software libre que conviertan el sonido en texto, contar con un sistema de subtitulación en directo (estenotipia computarizada), contar con el aprendizaje de la Lengua de Señas Ecuatoriana.

9. Cuando fue invitado a reuniones para dialogar sobre el apoyo que recibiría en la PUCE, por lo general, quién le acompañó: tres participantes respondieron que normalmente asistían solos; un participante señaló que no asistió a ninguna reunión.

10. Cuándo empezó a usar los apoyos en la Universidad: dos participantes señalaron que usaron apoyos antes de iniciar los semestres en la Universidad; un participante señaló que durante la primera semana del semestre y un participante en el primer mes del semestre.

11. Sobre lo que acontece en el aula: Le pidieron autorización para hablar con sus compañeros sobre su situación de sordera: los cuatro participantes señalaron que no les pidieron autorización.

12. En el aula, los docentes solicitan ubicar las mesas en forma de $\mathrm{U}$ o en círculo: dos participantes señalaron que a veces lo hacen y dos participantes indicaron que no lo solicitan.

13. Los docentes se dirigen a usted cuando explican la clase: un participante señaló que sí, uno señaló que a veces y dos indicaron que no se dirigen a su persona.

14. Durante la clase, los docentes se mueven mucho dificultando su lectura labial: tres participantes señalaron que los docentes sí se mueven mucho y un participante indicó que a veces.

15. Los docentes entregan los contenidos de la materia al inicio del semestre: dos participantes indicaron que a veces entregan contenidos y dos señalaron que no.

16. Los docentes utilizan apoyos visuales como láminas, gráficos, fotos, dibujos, diapositivas: dos participantes señalaron que sí y dos indicaron que a veces.

17. Las películas o videos que se proyectan en clase tienen subtítulos: tres participantes señalaron que no y un participante respondió a veces. 
18. Los docentes al inicio de clase le entregan un marco conceptual del contenido de esa clase: los cuatro participantes respondieron que no.

19. Los docentes le hacen participar y le preguntan directamente: un participante respondió que sí le hacen participar; un participante respondió que a veces le preguntan directamente y los otros dos señalaron que no.

20. Los docentes se aseguran que haya comprendido los contenidos de la clase: dos participantes señalaron que a veces y dos indicaron que no se aseguran.

21. Los docentes modifican y adaptan los contenidos para presentarlos visualmente: un participante señaló que sí adapta los contenidos; dos participantes indicaron que a veces y un participante señaló que no los modifican.

22. Durante la clase, los docentes se mueven mucho por el aula dificultando la lectura labial: tres participantes señalaron que los docentes sí se mueven mucho y un participante indicó que a veces.

23. Has recibido los contenidos de las materias previamente al inicio del semestre: un participante señaló que sí; un participante indicó que a veces y dos participantes respondieron no haber recibido los contenidos de la materia.

24. Los docentes tienen una actitud de aprendizaje sobre su situación de sordera: tres participantes señalaron que los docentes tienen una actitud de aprendizaje sobre la sordera y un participante indicó que no.

25. Cuál es su actitud en clase generalmente: tres participantes señalaron tener una actitud activa y un participante señaló ser pasivo.

26. Participa en las discusiones o debates en el aula: dos participantes señalaron que sí son participativos en el aula; un participante indicó que a veces y el otro que no.

27. Durante la hora de clase, cuando no entiende algo, pide que le repitan: tres participantes indicaron que sí piden que les repitan lo que no han entendido y un participante señaló que no lo pide.

28. Qué idioma extranjero tuvo que aprobar: los cuatro participantes señalaron el Inglés.

29. Cómo le resultó aprobar este segundo idioma: dos participantes señalaron que en lo oral y lo escrito les 
resultó muy fácil (ambos participantes están optando en la Universidad por una segunda profesión al momento de la encuesta); dos participantes indicaron que tanto en lo oral como en lo escrito les resultó muy difícil.

30. En general, se ha sentido respetado porque usa audífonos para oír: dos participantes señalaron que sí se han sentido respetados y dos participantes indicaron que no.

31. Sobre lo que le gusta y disgusta en la Universidad: Los docentes: dos participantes señalaron que sí les agradan los docentes; un participante que no y la otra participante ha marcado ambas respuestas, se podría interpretar como más o menos.

32. Obtiene buenas notas: Ios cuatro participantes señalaron que sí les gusta obtener buenas calificaciones.

33. Aprender: los cuatro participantes respondieron positivamente.

34. Tener muchos amigos: tres participantes señalaron que sí les gusta tener amigos y un participante ha marcado ambas respuestas, se podría interpretar como más o menos.
35. Sentirse apoyado para hacer bien las actividades que le solicitan: los cuatro participantes respondieron positivamente.

36. Disfrutar de la mayoría de las clases: los cuatro participantes respondieron positivamente.

37. Tener la oportunidad de desenvolverse con eficiencia: Ios cuatro participantes respondieron positivamente.

38. Sentirse respetado porque las personas son amables con él/ella: los cuatro participantes respondieron positivamente.

39. Ser más independiente y autónomo: los cuatro participantes respondieron positivamente.

40. Ser yo mismo/a y sentir que sí encajo en la Universidad: Ios cuatro participantes respondieron positivamente.

41. Participar de los trabajos en grupo con gusto: dos participantes señalaron que sí les gusta el trabajo grupal; un participante indicó que no y el otro participante ha marcado ambas respuestas, se podría interpretar como más o menos. 
42. Contar con aulas equipadas con pizarras interactivas: tres participantes señalaron que sí les gustaría y un participante indicó que no.

43. Hacer trabajos que no entiende: dos participantes indicaron que sí lo hacen y dos participantes señalaron que les disgusta hacer trabajos que no entienden.

\section{Tener que escribir mucho} en los exámenes: un participante señaló que sí le gusta escribir mucho y tres participantes indicaron que les disgusta escribir mucho en los exámenes.

45. De la pregunta ¿Qué actividades le hicieron sentir MENOS estresado en la Universidad? tenemos: Deporte: dos participantes respondieron afirmativamente y para dos participantes no es la opción.

46. Hacer meditación: los cuatro participantes respondieron negativamente.

47. Escuchar música: dos participantes señalaron que la música les baja las tensiones y para dos participantes no es la opción.

48. Recibir apoyo psicológico: una participante respondió afirmativa- mente y tres respondieron que no es la opción.

49. Conversar con personas que entienden sobre su situación de sordera: dos participantes respondieron positivamente y para dos participantes no es la opción.

50. Comer: un participante respondió afirmativamente y para tres no es la opción.

51. Beber: un participante respondió afirmativamente y para tres participantes no aplica.

52. Cuando se sentía ansioso/a a qué lugar de la Universidad se dirigía: Centro Médico: los cuatro participantes respondieron negativamente.

53. Rehabilitación: los cuatro participantes respondieron negativamente.

54. Centro de Psicología Aplicada: los cuatro participantes respondieron negativamente.

55. Promoción de la Salud: Ios cuatro participantes respondieron negativamente.

56. Al Servicio de Asesoría a la Discapacidad de la DGE: los cuatro participantes respondieron negativamente. 
57. Cashapamba: los cuatro participantes respondieron negativamente.

58. Biblioteca General: un participante respondió afirmativamente y tres participantes respondieron negativamente.

59. Pastoral Universitaria: Ios cuatro participantes respondieron negativamente.
60. Centro de Informática: los cuatro participantes respondieron negativamente.

61. Comedores de la Universidad: tres participantes respondieron positivamente y un participante negativamente.

62. Jardines de la Universidad: tres participantes respondieron positivamente y un participante negativamente.

\section{CUARTO MOMENTO: CULMINACIÓN DE LA CARRERA ACADÉMICA}

1. De la muestra se tuvo que dos participantes no concluyeron la carrera universitaria -se retiraron en 3 ro y 4to semestres- y dos participantes se encontraban en proceso de elaboración de tesis.

2. Los cuatro participantes señaIaron que eligieron correctamente su carrera.

3. A los participantes se les preguntó ¿qué hicieron? cuando se presentó algún problema relacionado con su situación de sordera: respondieron en el siguiente orden de prioridad: que contaban a la familia, a un amigo/a, al docente de confianza y al tutor desig- nado; no fueron consideradas las opciones de recurrir a los servicios estudiantiles como la DGE, el Centro Médico, ni al asesor en discapacidad.

4. Ante la pregunta ipor qué estudiar en la PUCE? las respuestas fueron: tres participantes respondieron que les encanta estudiar, porque necesitan un título para trabajar en lo que quieren y porque quieren aprender más; dos participantes señalaron estar interesados en la investigación y un participante señaló que la familia esperaba que fuera a la universidad.

5. Se les preguntó si alguna vez experimentaron discriminación relacio- 
nada con su situación de sordera por parte de los compañeros, docentes, tutores u otras personas involucradas en su educación superior mientras estudiaron en la PUCE:

- Tres participantes señalaron que tuvieron problemas con la comprensión de la dicción del docente y también que hubo indiferencia ante sus necesidades;

- Dos participantes señalaron haber recibido hostigamiento e intimidación (Bullying); haber tenido problemas para comprender los contenidos en el aula y los contenidos de la materia y cuando se generaliza sobre lo que se puede o no se puede hacer en relación a la sordera;

- Un participante señaló haber sido excluido de las actividades y haber tenido problemas con la comprensión durante las conferencias en los auditorios.

6. Se preguntó a los participantes qué entendían por Inclusión Educativa, se obtuvieron las siguientes respuestas:

\section{Que el estudiante con sordera se inte-} gre a la sociedad.

2. Que a las personas discapacitadas nos integren en varias cosas y con nuestros derechos, pero eso no se ve ya que muchos somos discriminados.

3. Tener derecho a la igualdad de oportunidades, en este caso, el acceso a formarme profesionalmente sin barreras de comunicación.

4. Que la Universidad permita el ingreso de personas con discapacidad, que faciliten información, den buen trato, las ayudas didácticas, que entrenen a profesores para relacionarse bien y correctamente con los estudiantes discapacitados, que no haya persecución ni discriminación por ignorancia.

La información obtenida en esta investigación permitió la elaboración de la Guía para la Atención Educativa de los Estudiantes Sordo Parlantes a nivel de Educación Superior en la PUCE-Quito que no pretende ser única o inamovible, por el contrario, el tiempo y su contrastación con la realidad permitirá mejorarla. También se produjo un video como apoyo visual que contiene orientaciones dirigidas a los docentes para facilitar una adecuada inclusión educativa en el aula. 


\section{DISCUSIÓN}

La evasión de los estudiantes sordos a no participar en investigaciones sobre la sordera es notoria, como lo indica la configuración de la muestra de este estudio que no logró concretar el quinto caso. Es fundamental que los estudiantes sordo parlantes desempeñen un papel activo en la resolución de sus propias dificultades y no ser únicamente receptores pasivos de soluciones dadas por los oyentes.

Si la Universidad busca convertirse en un sistema educativo incluyente, requiere reflexionar sobre el concepto de equidad que articula la estructura del sistema educativo universitario con la igualdad de oportunidades para todo el estudiantado (Echeita, 2014). Ni las características personales, ni la sordera, ni la estructura de la Universidad deberían ser barreras que impidan disfrutar del derecho a una educación de calidad.

La inclusión educativa es un proceso que desafía a la comunidad universitaria y al docente a tomar acciones propositivas para asegurar una relación comunicativa y de aprendizaje con el estudiante sordo parlante quien en el aula es visto como el estudiante con dificultades para aprender y no se plantea ni se cuestiona la dificultad del docente para enseñar (Echeita, 2014), puesto que aún no se considera a la diversidad como una naturalidad sino como un dilema o controversia (Booth, T.; Ainscow, M.; Kingston, D., (2006).

Se requiere impulsar procesos continuos de sensibilización para que la comunidad universitaria comprenda cómo la presencia de la sordera en el estudiante es valiosa en sí misma porque hace referencia a su singularidad, además de favorecer la oportunidad al docente de plantearse una didáctica diferente en el aula.

Los procesos de inclusión educativa a nivel universitario son viables y son proclives a ser mejorados como lo señala el $54.54 \%$ de respuestas que indican que no se les ofreció información de alternativas técnicas ni de apoyos visuales pero que les hubiera sido de utilidad.

\section{CONCLUSIONES}

1. La inclusión exige una nueva forma de pensar sobre la diversidad. La inclusión educativa coloca en el centro del sistema al estudiante y a la acción educativa que demanda flexibilidad tanto en la relación docente-estu- 
diante como en la planificación de la práctica didáctica.

2. Los dilemas son propios de los procesos de inclusión y se podría decir que la Universidad ha de procurar realizar un diagnóstico de su situación de inclusión -a todo nivel- para revisar sus políticas institucionales, comprender el término inclusión desde el nivel de las autoridades hasta el espacio del aula, formar al personal docente en inclusión, educar a la Universidad en procesos de inclusión y llevar a la práctica inclusiva todos los servicios que proporciona la Universidad.

3. Los resultados señalan que la PUCE-Quito cuenta con la decisión política para llevar a cabo procesos de inclusión. La creación de la Coordinación para la Inclusión (2016) perteneciente a la Dirección General de Estudiantes de la Universidad es el organismo que articulará tanto los procesos de sensibilización a la comunidad universitaria sobre educa- ción inclusiva como de diseñar propuestas de adaptaciones y servicios de atención para los estudiantes.

4. El lugar que la persona sorda parlante tiene en el mundo, de ninguna manera se reduce a la sordera que presenta. Por lo tanto, es importante comprender que la situación de sordera en la vida de la persona implica una manera diferente de estar-enel-mundo a nivel comunicativo, informativo, lingüístico, cognitivo, del aprendizaje, de lo social y lo personal.

5. Para el personal docente universitario se requiere también una formación en inclusión educativa -y para el presente caso formación en sordera-con el propósito de lograr que la enseñanza en el aula sea realizada con el apoyo de las ayudas técnicas, de la TICs y las Tecnologías Alternativas adecuadas para así vencer las barreras de comunicación y de acceso a la información que requiere el estudiante sordo parlante. 


\section{BIBLIOGRAFÎA}

Naciones Unidas. (2014). Informe del Comité de las Naciones Unidas al Infome del Ecuador. CRPD/C/ECU/ $\mathrm{CO} / 1, \mathrm{p} .7$.

Naciones Unidas. (2008). Aprobada el 13 de diciembre de 2006 en la Asamblea General de las Naciones Unidas. Ratificada por el Ecuador el 3 de abril de 2008.

Extraída en diciembre de 2016 https:// es.wikipedia.org/wiki/Convención_Internacional_sobre_los_ Derechos_de_las_Personas_ con_Discapacidad

Echeita Sarrionandia, G., (2014). Educación para la inclusión o educación sin exclusiones. Bogotá: Narcea Ediciones de la U, p. 157.

Escribano, A.; Martínez, A. (2013). Inclusión educativa y profesorado inclusivo: aprender juntos para aprender a vivir juntos. Madrid: Narcea Ediciones, p. 16.

CONADIS, extraída en abril 2017, https:// www.consejodiscapacidades. gob.ec/

Booth, T.; Ainscow, M.; Kingston, D., (2006). Index para la inclusión.
Extraído en enero 2017, http:// www.eenet.org.uk/resources/ docs/Index\%20EY\%20Spanish. pdf

Fundación Vivir la Sordera. (2014). Manual sobre la Sordera: dirigido a profesionales que ofrecen servicios a niños, niñas y adolescentes sordos y a sus familias. Quito.

INSOR. (2004). Frecuencia Modulada (FM). Extraída en enero 2017.

https://www.sonoraudifonos.com/sonor-audifonos/equipos-fm-frecuencia-modulada

Estenotipia. Extraída en diciembre 2016. Extraída en diciembre 2016. Fuente: https://ayudatec. cl/2011/10/11/ique-es-la-estenotipia/

Instituto de Ingeniería Eléctrica (2014). Aro Magnético o Bucle Magnético. Extraída en enero de 2017. Fuente: Ayudando a oír mejor: el aro magnético de Eirea, G., Montevideo, https://iie.fing.edu.uy

Carrera, E. (2017). Guía para la inclusión a nivel de educación superior. Descripción de las condiciones de es- 
tudio para los estudiantes sordos parlantes en la PUCE-Quito: análisis exploratorio de cinco casos de estudio. http://repositorio.puce. edu.ec/handle/22000/13819

Carrera, E. (2017). Video sobre la atención educativa a los universitarios sordo parlantes.

https://youtu.be/-61fzV85cuw
PUCE. (2013). Políticas de Acciones Afirmativas e Inclusión de Profesores, Estudiantes y Trabajadores de la PUCE. Documento firmado por el Dr. Manuel Corrales Pascual, S.J. Rector de la PUCE. Quito. 